10 Moran BJ, Taylor MB, Johnson CD. Percutaneous endoscopic gastrostomy Br F Surg 1990;77:858-62.

1 Ponsky JL, Gauderer MWL; Stellato TA, Aszodi A. Percutaneous approaches to enteral alimentation. Am 7 Surg 1985;149:102-5.

12 Larson DE, Burton DD, Schroeder KW, DiMagno EP. Percutaneous endoscopic gastrostomy. Indications, success, complications, and mortality in 314 consecutive patients. Castroenterology 1987;93:48-52.

13 Benya R, Mobarhan S. Enteral alimentation: administration and complications. F Am Coll Nutr 1991;10:209-19.

14 Keohane PP, Attrill H, Jones BJM, Silk DBA. Limitations and drawbacks of fine bore nasogastric feeding tubes. Clin Nutr 1983;2:85.

15 Foutch PG, Woods CA, Talbert GA, Sanowski RA. A critical analysis of the Sacks-Vine gastrostomy tube: a review of 120 consecutive procedures. Am F Gastroenterol 1988;83:812-5.

16 Wolfsen HC, Kozarek RA, Ball TJ, Patterson DJ, Botoman VA, Ryan
JA. Long-term survival in patients undergoing percutaneous endoscopic gastrostomy and jejunostomy. Am f Gastroenterol 1990;85:1120-2.

17 Hogan RB, DeMarco DC, Hamilton JK, Walker CO, Polter DE. Percutaneous endoscopic gastrostomy - to push or pull. Gastrointest Endosc 1986;32:253-8.

18 Kirby DF, Craig RM, Tsang T-K, Plotnick BH. Percutaneous endoscopic gastrostomies: a prospective evaluation and review of the literature. 7 Parenter Enteral Nutr 1986;10:155-9.

19 Cogen R, Weinryb J. Aspiration pneumonia in nursing home patients fed via gastrostomy tubes. Am F Gastroenterol 1989;84:1509-12.

20 Allison MC, Morris AJ, Park RHR, Mills PR. Percutaneous endoscopic gastrostomy tube feeding may improve outcome of late rehabilitation following stroke. I R Soc Med 1992;85:147-9.

(Accepted 23 March 1992)

\title{
Trends in deliberate self poisoning and self injury in Oxford, 1976-90
}

\author{
Keith Hawton, Joan Fagg
}

\begin{abstract}
Objective-To review trends in deliberate self poisoning and self injury (attempted suicide) over 15 years (1976-90) on the basis of general hospital referrals.
\end{abstract}

Design-Prospective data collection by computerised monitoring system.

Setting-Teaching general hospital.

Subjects -All patients aged 15 and over $(n=9605)$ referred to the hospital after episodes $(n=13340)$ of deliberate self poisoning or self injury.

Main outcome measures-Rates based on population of Oxford city; changes in substances used for self poisoning; history and repetition of attempts; and rates of admission to the hospital and of referral to the psychiatric service.

Results-Attempted suicide rates for women declined during the late 1970 s and early 1980 s but increased again during the late 1980s. Those for men remained relatively steady throughout the period. Highest mean annual rates occurred in women aged 15-19 (711/100000) and in 20-34 year old men $(334 / 100000)$. The proportion of overdoses with paracetamol increased from $14.3 \%(125 / 873)$ in 1976 to $42 \%(365 / 869)$ in $1990\left(\chi^{2}\right.$ for trend $\left.=481, p<0.01\right)$. Throughout the period the proportions of referred patients admitted to hospital and of those attempting suicide for the first time (over two thirds) did not decrease. Annual rates of repetition of attempts by women declined from $15 \cdot 1 \%(257 / 1700)$ in $1976-8$ to $11.9 \%(161 / 1356)$ in $1987.9\left(\chi^{2}\right.$ for trend $=7.8$, $\mathbf{p}<0.01)$. Lower repetition rates occurred in women admitted to hospital and referred to the psychiatric service $(431 / 4585,9.4 \%)$ than in those not referred $\left(42 / 235,17.9 \% ; \chi^{2}=17 \cdot 2, p<0.0001\right)$.

Conclusions - Rates of attempted suicide declined in the 1970s and early 1980s, in women, but there are probably at least 100000 hospital referrals a year in England and Wales because of this problem. Prevention of paracetamol self poisoning requires urgent attention, and psychosocial assessment should be conducted with as many of those who attempt suicide as possible.

University Department of Psychiatry, Warneford Hospital, Oxford OX3 7JX Keith Hawton, consultant psychiatrist and clinical lecturer

Joan Fagg, research assistant

Correspondence to:

Dr Hawton.

BMF 1992;304:1409-11 women to hospital and the second most common such reason for men. ${ }^{4}$ This paper reviews trends in referrals for attempted suicide to the general hospital in Oxford over the 15 years $1976-90$ and is based on information collected in a computerised monitoring system.'

\section{Method}

We studied the attempts of people aged 15 and over referred to the general hospital in Oxford because of self poisoning or self injury. The general hospital receives all referred patients from Oxford city and the surrounding area. Patients referred after self poisoning or self injury are identified by the monitoring system, irrespective of whether they are referred to the emergency psychiatric service in the hospital. Those referred to the service $(83 \cdot 2 \%)$ received a detailed psychosocial assessment ${ }^{4}$ by a specially trained psychiatric nurse, psychiatrist, or social worker, after which a data sheet was completed for entry to the computerised monitoring file. Through scrutiny of accident and emergency department records a limited amount of information was also available on patients referred to the hospital but not to the psychiatric service.

For those findings which are based on rates the data have been analysed for referrals from Oxford city only. This is because the rest of the hospital catchment area is ill defined. The population figures for Oxford city are midyear estimates and were provided by the Office of Population Censuses and Surveys. Age and sex specific rates per 100000 population were calculated, with appropriate midyear population estimates as the denominators.

\section{Results}

REFERRALS TO GENERAL HOSPITAL

During the 15 year period (1976-90) 9605 people were referred to the general hospital as a result of 13340 episodes of deliberate self poisoning or self injury. A total of 5961 patients $(62 \cdot 1 \%)$ were women.

The rates of attempted suicide for Oxford city residents declined in women between the late 1970s and 1985 but rose again later in the study period, whereas those for men remained relatively steady throughout (table). The highest rates in women were consistently in the 15-19 age group (mean annual rate $711 / 100000)$ and in men generally in the 20-34 age group (mean annual rate $334 / 100000$ ).

Extrapolation from the age and sex specific rates of attempted suicide in Oxford city during 1989 and 1990 to the appropriate population data for England and Wales suggests that approximately 120000 patients 
Rates of referral of people aged 15 or over from $O x$ ford city population to general hospital in Oxford after deliberate self poisoning or self injury, 1976-90

\begin{tabular}{ccccccccc}
\hline & \multicolumn{2}{c}{ Men } & & \multicolumn{2}{c}{ Women } & & \multicolumn{2}{c}{ Total } \\
\cline { 2 - 5 } \cline { 7 - 8 } \cline { 7 - 8 } Year & $\begin{array}{c}\text { Rate per } \\
100000\end{array}$ & No & & $\begin{array}{c}\text { Rate per } \\
100000\end{array}$ & No & & $\begin{array}{c}\text { Rate per } \\
100000\end{array}$ & No \\
\hline 1976 & 238 & 119 & & 497 & 248 & & 367 & 367 \\
1977 & 280 & 139 & & 470 & 234 & & 375 & 373 \\
1978 & 276 & 138 & & 490 & 242 & & 382 & 380 \\
1979 & 220 & 110 & & 391 & 192 & & 305 & 302 \\
1980 & 251 & 126 & & 379 & 183 & & 314 & 309 \\
1981 & 240 & 121 & & 384 & 188 & & 311 & 309 \\
1982 & 246 & 124 & & 391 & 192 & & 318 & 316 \\
1983 & 251 & 127 & & 354 & 173 & & 302 & 300 \\
1984 & 209 & 103 & & 397 & 190 & & 301 & 293 \\
1985 & 211 & 104 & & 296 & 143 & & 253 & 247 \\
1986 & 241 & 119 & & 344 & 168 & & 292 & 287 \\
1987 & 227 & 111 & & 303 & 148 & & 265 & 259 \\
1988 & 213 & 103 & & 316 & 154 & & 265 & 257 \\
1989 & 277 & 134 & & 386 & 190 & & 332 & 324 \\
1990 & 272 & 133 & & 363 & 181 & & 318 & 314 \\
Mean rate & 243 & 121 & & 384 & 188 & & 314 & 309 \\
\hline
\end{tabular}

aged 15 and over might currently be referred to general hospitals in England and Wales each year as a result of suicide attempts.

\section{METHODS USED}

Self poisoning was involved in $87 \cdot 3 \%(11647 / 13340)$ of episodes, self injury in $9 \cdot 9 \%(1326 / 13340)$, and both methods in $2 \cdot 8 \%(367 / 13340)$. There was a pronounced decrease during the 15 years (figure) in the use of minor tranquillisers and sedatives in overdoses $\left(\chi^{2}\right.$ for trend $\left.=433, p<0.01\right)$, presumably reflecting reduction in prescribing. ${ }^{6}$ The use of nonopiate analgesics for self poisoning increased $\left(\chi^{2}\right.$ for trend $=195, p<0.01)$. This was entirely due to a large increase in the proportion of overdoses with paracetamol $\left(\chi^{2}\right.$ for trend $\left.=481, \mathrm{p}<0.01\right)$.

\section{NEW ATTEMPTS AND REPEATED ATTEMPTS}

The proportion of people attempting suicide for the first time did not decline over the study period, averaging $69 \cdot 5 \%(5519 / 7938)$. Thus nearly a third of patients had a history of earlier attempts.

The annual rate of repetition (repetition and referral to the same general hospital within a year of any attempt within one calendar year) decreased in women, the mean annual repetition rate being $15 \cdot 1 \%$ $(257 / 1700)$ in $1976-8$ and $11.9 \%(161 / 1356)$ in $1987-9$ $\left(\chi^{2}\right.$ for trend $=7 \cdot 8, p<0 \cdot 01$ ). There was no change in men.

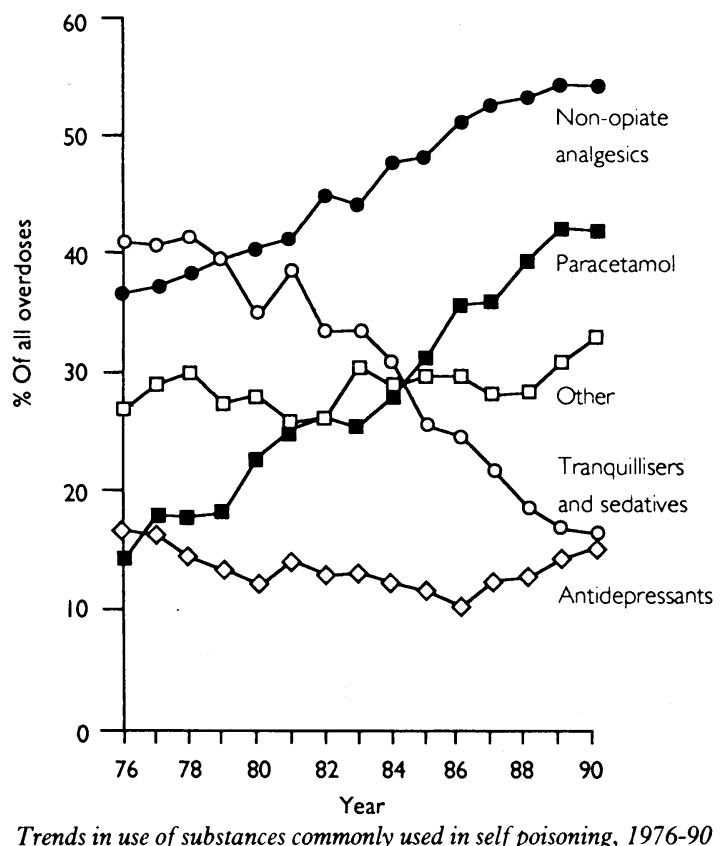

Admission to hospital and referral to psychiatric service

Of the 13340 patients referred to the general hospital during the study period, $11070(83.0 \%)$ were admitted to a hospital bed and $11104(83 \cdot 2 \%)$ were referred to the general hospital psychiatric service. Neither percentage changed significantly during the study period. Referral to the psychiatric service occurred for $92.5 \%(10236 / 11070)$ of the patients who were admitted and only $38 \cdot 2 \%(868 / 2270)$ of those who were not admitted.

Annual repetition rates during the year after the attempts did not differ greatly between those admitted to hospital $(10.3 \%, 784 / 7591)$ and those who were not $(11 \cdot 3 \%, 156 / 1377)$. However, a significant difference in repetition was found in women admitted to hospital; a smaller proportion of those referred to the psychiatric service attempted suicide again than those who were not referred $(9 \cdot 4 \%, 431 / 4585 v 17 \cdot 9 \%, 42 / 235$; $\left.\chi^{2}=17 \cdot 2, p<0.0001\right)$. Psychiatric referral was not associated with any difference in repetition rates in men who had attempted suicide.

\section{Discussion}

Although rates of attempted suicide in Oxford declined during the late 1970s and early 1980s, as found elsewhere in the United Kingdom, ${ }^{78}$ this trend was largely reversed in the late $1980 \mathrm{~s}$. On the basis of our findings for 1989 and 1990, as many as 120000 patients aged 15 years and over may be referred to general hospitals each year in England and Wales. Because the Oxford rates are based on a city population and urban rates tend to be higher than those in rural areas, ${ }^{9}$ this may be an overestimate. However, the overall figure is unlikely to be below 100000 , of whom nearly two thirds would be aged 15 to 34 . Since more than two thirds of those who attempt suicide are doing so for the first time, a substantial decline in this problem is unlikely in the near future unless there is a change in the factors that predispose to or precipitate attempts.

By the end of the study period the incidence of self poisoning by paracetamol had increased to four out of 10 overdoses. In the light of paracetamol's hepatic toxicity a way should be found to reduce the likelihood of self poisoning with paracetamol.

Contrary to reports from elsewhere, ${ }^{10-12}$ we found no evidence of a reduction in the proportion of people attempting suicide who were referred to a general hospital and who were then admitted. This may partly reflect the fact that Oxford has a major clinical service for those who attempt suicide ${ }^{5}$ and special attention has always been paid to this population of patients. In keeping with the Department of Health's guidelines ${ }^{13}$ nearly all those who attempt suicide are referred for psychiatric assessment (although referral rates are much lower in those not admitted to hospital than in those admitted). Support for this policy is provided by the lower rate of repetition found in patients assessed than in those not assessed, at least in women. This is in keeping with the outcome of studies of psychosocial aftercare programmes. ${ }^{14}$ All general hospitals should have a readily available service for psychosocial assessment of patients who have attempted suicide and should ensure that as many as possible are referred to the service.

We thank members of the psychiatric emergency service in the John Radcliffe Hospital and Leicester Gill in the Oxford department of clinical epidemiology for their help in maintaining the monitoring system for patients who have attempted suicide. Pat Wells and Jackie Mills assisted with the data collection. The research was supported by grants from Oxford Regional Health Authority and the Medical Research Council. 
Alderson MR. Self-poisoning - what is the future? Lancet 1974;i:1040-3

Kreitman N, Schreiber M. Parasuicide in young Edinburgh women, 1968-75. Psychol Med 1979;9:469-79.

3 Bancroft J, Skrimshire A, Reynolds F, Simkin S, Smith J. Self-poisoning and self-injury in the Oxford area: epidemiological aspects 1969-73. Brf Prev Soc Med 1975;29:170-7.

4 Hawton K, Catalan J. Attempted suicide: a practical guide to its nature and management (2nd ed). Oxford: Oxford University Press, 1987.

5 Hawton K, Gath D, Smith E. Management of attempted suicide in Oxford. BMF 1979; ii: 1040-2.

6 Forster DP, Frost CEB. Medicinal self-poisoning and prescription frequency. Acta Psychiatrica Scand 1985;71:657-74.

7 Brewer C, Farmer R. Self-poisoning in 1984: a prediction that didn't come true. $B M F$ 1985;290:391

8 Platt S, Hawton K, Kreitman N, Fagg J, Foster J. Recent clinical and epidemiological trends in parasuicide in Edinburgh and Oxford: a tale of two cities. Psychol Med 1988;18:405-18.
9 Skrimshire AM. A small area analysis of self-poisoning and self-injury in the region of Oxford. $\mathcal{F}$ Biosoc Science 1976;8:85-112.

10 Blake DR, Mitchell JRA. Self-poisoning: management of patients in Nottingham, 1976. BMF 1978;i: 1032-5.

1 Owens DW, Jones SJ. The accident and emergency department managemen of deliberate self-poisoning. $\mathrm{Br} \mathcal{F}$ Psychiatry 1988;152:830-3.

12 Black D, Creed F. Assessment of self-poisoning patients by psychiatrists and junior medical staff. f R Soc Med 1988;81:97-9.

13 Department of Health and Social Security. The management of deliberate selfharm. London: Department of Health and Social Security, 1984 (HN(84)25.)

14 Hawton K. Controlled studies of psychosocial intervention following attempted suicide. In: Kreitman N, Platt SD, eds. Current research on suicide and parasuicide. Edinburgh: Edinburgh University Press, 1989: $180-95$.

(Accepted 23 March 1992)

\title{
Gonad protection in young orthopaedic patients
}

\author{
Nicholas Kenny, John Hill
}

\begin{abstract}
Objective-To determine whether gonad shields are correctly positioned on the pelvic radiographs of children with slipped capital femoral epiphysis.

Design-Retrospective study of radiographs taken of children treated by in situ pinning of slipped capital femoral epiphysis between 1 January 1983 and 31 December 1988.
\end{abstract}

Setting-Three teaching hospitals in north west England.

Patients - 32 patients with complete set of radiographs.

Results - An average of 10.8 anteroposterior pelvic radiographs plus 8.9 lateral hip radiographs had been performed per patient. Gonad shields had been completely omitted in $137(40 \%)$ anteroposterior pelvic radiographs performed on the 32 patients at the time of completion of the study. In $100(29 \%)$ the gonad shields were adequately protecting the gonads, but in $109(31 \%)$ the gonad shields were not protecting the gonads due to incorrect positioning of the shield. The incorrect positioning of the gonad shields was more commonly found in girls than boys (64 $v 45$; $\mathbf{p}<0.012$ ), presumably because of the difficulty in determining gonadal position in relation to surface landmarks. Absence of gonad shields was also more commonly seen in girls $(82 v 55 ; \mathrm{p}<0.005)$, but this is not easily explained.

Conclusions-Gonad shields are not protecting the gonads in a large percentage of anteroposterior pelvic radiographs $(71 \%)$ because they have been omitted or inadequately placed. This avoidable excess radiation exposure to the gonads, combined with the inability to shield the gonads in lateral hip radiographs and the large number of radiographs performed, results in the gonads receiving a higher dose of radiation than may otherwise be the case, and may increase the potential for disease in the future offspring of these patients.

\section{Ancoats Hospital, \\ Manchester M4 6EB \\ Nicholas Kenny, orthopaedic registrar}

\section{Royal Preston Hospital,} Pulwood, Preston, Lancashire PR2 4HT John Hill, consultant in rediology and nuclear medicine

Correspondence to: $\mathrm{Mr}$ Kenny.

BMF 1992;304:1411-3

\section{Introduction}

Diagnostic radiology provides an essential method of investigating and monitoring the progress of hip disorders in children. One such disorder is slipped capital femoral epiphysis, and numerous pelvic radiographs may be required throughout the course of diagnosis and treatment.

The effects of ionising radiation are cumulative. The gonads are particularly sensitive to the effects of radiation, especially at or below reproductive age. Inadequate shielding of the gonads will increase the exposure of these organs to radiation and its harmful effects.
The aim of this study was to determine the extent of gonadal radiation exposure due to the inadequate positioning of gonad shields in children with slipped capital femoral epiphysis.

\section{Patients and methods}

The clinical notes and radiographs of all children treated by pinning in situ for slipped capital femoral epiphysis in three hospitals in north west England between 1 January 1983 and 31 December 1988 were obtained. Any child with an incomplete set of radiographs was excluded from the study.

The total number of anteroposterior pelvic and lateral hip radiographs taken over the six year period for each child was determined. The presence or absence of gonad shields in all anteroposterior pelvic radiographs was recorded, and if shields were present whether the gonads were effectively protected was recorded. The position of the gonads in boys was considered to be within the scrotal sac, which is readily visible on a plain pelvic radiograph. The female gonads were considered to rest adjacent to the ischial spines, which are also readily visible on a plain pelvic radiograph. The gonad shield was considered to be inadequately positioned when these areas were not fully shielded. Extreme examples of bad positioning and inadequate size are shown in the figures. Positioning of the shields in boys and girls was compared by Kendall's $\tau$ test.

\section{Results}

There were 32 children available for the study, average age 12.5 (range $8-15$ ) years. There were 15 boys and 17 girls. Twelve children (38\%) had bilatera slips. A total of 346 anteroposterior pelvic radiographs

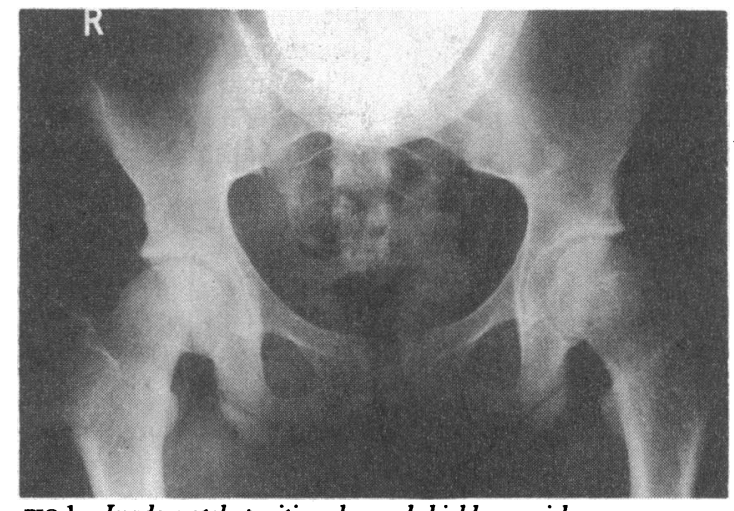

FIG 1-Inadequately positioned gonad shield on a girl 